\title{
PEMODELAN PERILAKU KERUNTUHAN BALOK TINGGI AKIBAT PENURUNAN PONDASI DI ATAS TANAH LUNAK KOTA BANJARMASIN MENGGUNAKAN METODE ELEMEN HINGGA 3D
}

\author{
oleh : \\ Elia Anggarini \\ Teknik Sipil Universitas Muhammadiyah Banjarmasin \\ Email : lia.teweh@gmail.com \\ Irwandy Muzaidi \\ Teknik Sipil Universitas Muhammadiyah Banjarmasin \\ Email : irwann.muzaidi@gmail.com
}

\begin{abstract}
Abstrak : Proses penurunan pondasi diakibatkan oleh terkompresinya lapisan tanah di bawah pondasi akibat beban struktur. Secara umum terdapat dua jenis penurunan yaitu penurunan segera dan penurunan konsolidasi. Jumlah kedua jenis penurunan ini merupakan penurunan total yang terjadi. Tanah lunak/ lempung memiliki kedua jenis penurunan ini. Perilaku dan karakteristik balok tinggi sangat berbeda dengan perilaku dan karakteristik balok yang mempunyai perbandingan normal. Pada balok tinggi akan dominan terjadi keruntuhan geser, dimana keruntuhan bersifat getas tanpa adanya peringatan berupa lendutan yang berarti. Pada balok tinggi digunakan beton mutu sangat tinggi agar ketahanan serta kekakuan struktur lebih seimbang. Metode penelitian yang digunakan adalah studi literatur dengan mendalami materi yang relevan meliputi berbagai buku teks, jurnal ilmiah, peraturan dan Standar Nasional maupun Internasional, membuat permodelan balok tinggi beton bertulang dengan menggunakan software ANSYS, membuat permodelan balok tinggi dengan variasi penurunan pondasi. Hasil dari penelitian ini untuk mendapatkan persamaan fungsi beban terhadap lendutan yang terjadi pada balok tinggi yang mengalami penurunan pondasi/ tumpuan dengan software ANSYS. Model tersebut adalah model EA.IM.BT.0, model EA.IM.BT.100, model EA.IM.BT.200, model EA.IM.BT.500 dan model EA.IM.BT.750 .
\end{abstract}

Kata Kunci : pondasi, ANSYS, lendutan, tanah lunak

Abstract : The process of decreasing the foundation is caused by the compression of the subsoil under the foundation due to structural loads. In general there are two types of decreases namely immediate decreases and consolidation decreases. The sum of these two types of decline is the total decrease that occurred. Soft / clay soils have both types of subsidence. The behavior and characteristics of the high beam are very different from the behavior and characteristics of the beam which have a normal comparison. In the deep beam the shear collapse will be dominant, where the collapse is brittle without warning of meaningful deflection. In deep beams very high strenght concrete is used so that the durability and structural stiffness are more balanced. The research method used is a literature study carried out by exploring relevant material, which includes various textbooks, scientific journals, regulations and National and International Standards, making modeling of reinforced concrete high beam using ANSYS software, making a high beam modeling with variations in reduction Foundation. The results of this study are to get the equation of the load function of deflection that occurs in high beams which have decreased foundation / footing with ANSYS Software. The models are EA.IM.BT.0.0 model, EA.IM.BT.100 model, EA.IM.BT.200 model, EA.IM.BT.500 model and EA.IM.BT.750 model.

Keyword : foundation, ANSYS, deflection, soft soil 


\section{Pendahuluan}

Pada saat sekarang pembangunan gedung bertingkat di Indonesia semakin banyak dipergunakan. Bangunan bertingkat umumnya digunakan sebagai gedunggedung pemerintah seperti perkantoran dan rumah sakit. Selain itu pembangunan gedung bertingkat di Indonesia dapat juga dijadikan sebagai investasi seperti apartement, hotel, mall, dll. Hal ini mengakibatkan kebutuhan akan lahan yang luas semakin sulit diperoleh sehingga pembangunan gedung bertingkat akan berpengaruh pada bentuk bangunan yang cenderung tidak beraturan.

Kota Banjarmasin merupakan kota berkembang, terutama di bidang infrastruktur, tidak sedikit bangunan besar di Kota Banjarmasin menggunakan elemen struktur berupa balok tinggi. Balok tinggi umumnya digunakan pada portal bentang panjang agar elemen mempunyai kekakuan yang tinggi. Kota Banjarmasin juga memiliki tanah rawa yang memiliki daya dukung sangat rendah secara menyeluruh. Dimana lapisan tanah kerasnya berada di antara kisaran $30 \mathrm{~m}$ sampai dengan $50 \mathrm{~m}$, sehingga dalam membangun suatu struktur bangunan digunakan tiang pondasi di bawah pondasi telapak. Akibatnya banyak sekali terdapat bangunan miring dan elemen struktur yang mengalami keruntuhan berupa deformasi dan keretakan. Daya dukung tanah di Banjarmasin dikenal memiliki nilai yang sangat rendah, sehingga dapat dilihat pada bangunan-bangunan yang ada di Kota Banjarmasin mengalami kemiringan yang diakibatkan oleh penurunan pondasi. Penelitian ini merupakan hasil permodelan komputer software ANSYS Versi ED. 9.00 terhadap perilaku keruntuhan elemen struktur balok tinggi beton bertulang mutu tinggi. Tujuan dari penelitian ini adalah untuk mengetahui perilaku balok tinggi akibat penurunan pondasi yang terjadi di atas tanah lunak.

\section{Perumusan Masalah}

Bagaimana perilaku daktilitas kurvatur yang terjadi pada balok tinggi yang mengalami penurunan pondasi/ tumpuan dengan bantuan software ANSYS.

\section{Penurunan Pondasi}

Proses penurunan pondasi diakibatkan oleh terkompresinya lapisan tanah di bawah pondasi akibat beban struktur. Secara umum terdapat dua jenis penurunan, yaitu 1) penurunan segera yang dikontribusikan oleh sifat elastik tanah dan terjadi segera setelah lapisan tanah menerima beban, dan 2) penurunan konsolidasi, yang terjadi akibat keluarnya sebagian kandungan air dari lapisan tanah sehingga tanah menjadi lebih mampat. Penurunan konsolidasi ini terjadi dalam rentang waktu yang lebih lama dan jauh lebih besar dibanding penurunan segera. Jumlah kedua jenis penurunan ini merupakan penurunan total yang terjadi. Tanah jenis lunak/ lempung memiliki kedua jenis penurunan ini.

Konsolidasi primer adalah yaitu penurunan yang disebabkan perubahan volume tanah selama periode keluarnya air pori dari tanah. Pada penurunan ini, tegangan air pori secara kontinyu berpindah ke dalam tegangan efektif sebagai akibat dari keluarnya air pori. Penurunan konsolidasi ini umumnya terjadi pada lapisan tanah kohesif. Pada akhir konsolidasi primer (setelah tegangan air pori $U=0$ ), penurunan pada tanah masih tetap terjadi sebagai akibat dari penyesuaian plastis butiran tanah. Tahapan konsolidasi ini dinamakan konsolidasi sekunder. 


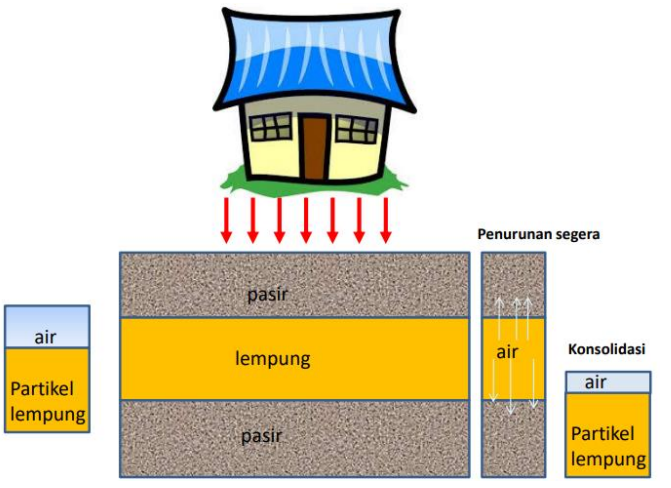

Gambar 1. Ilustrasi terjadinya konsolidasi primer

\section{Balok Tinggi}

Balok tinggi merupakan elemen struktural yang mempunyai rasio bentang balok dari as ke as terhadap tinggi balok yang tidak melebihi 2,0 untuk bentang sederhana $(\mathrm{L} / \mathrm{H}$ $<2,0)$ dan 2,5 untuk balok menerus $(\mathrm{L} / \mathrm{H}<$ 2,5 ) (Shahidul I., 2012). Balok tinggi banyak digunakan dalam dunia konstruksi seperti balok transfer geser, balok jembatan, dinding pondasi, dinding geser dan lain-lain. Berdasarkan hasil penelitian Patil (2013) dapat diketahui bahwa keruntuhan utama balok tinggi adalah disebabkan oleh retak geser diagonal yang terjadi pada badan balok dan semakin tinggi balok maka kekuatan lentur balok juga akan meningkat.

\section{Beton Bertulang Mutu Tinggi}

Beton mutu tinggi adalah beton yang mempunyai kuat tekan tinggi, ketahanan dan kemampuan yang tinggi terhadap berbagai keadaan lingkungan. Beton mutu tinggi juga memiliki modulus elistisitas yang tinggi, rendah permeabilitas dan ketahanan terhadap serangan dari beberapa kerusakan (Neville dan Aitcin, 1997). Menurut klasifikasi kekuatannya, beton mutu tinggi dengan kuat tekan $50 \mathrm{MPa}$ sampai $80 \mathrm{MPa}$ dan beton mutu sangat tinggi dengan kuat tekan lebih dari $80 \mathrm{MPa}$.
Grafik hubungan tegangan dan regangan beton mutu tinggi usulan Popovics dapat dilihat pada gambar 2 di bawah ini.

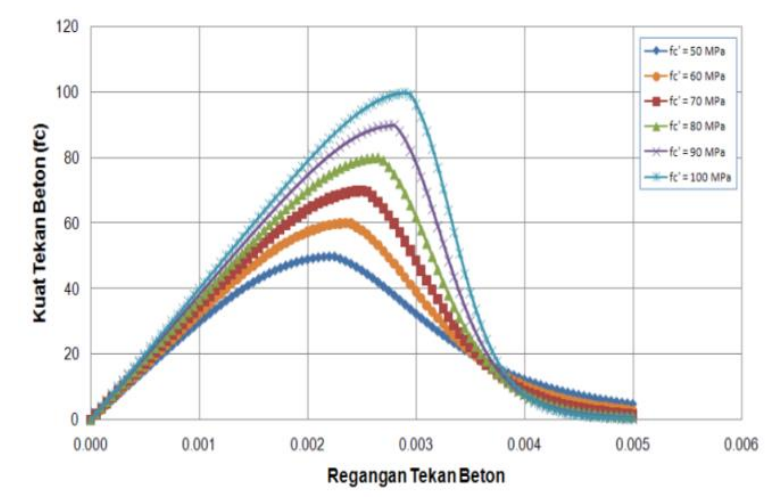

Gambar 2. Grafik Tegangan-Regangan Beton Mutu Tinggi dan Mutu Sangat Tinggi Usulan Popovics (1973)

\section{Metodologi Penelitian}

Metode penelitian yang digunakan adalah: Studi literatur dilakukan dengan mendalam materi yang relevan dengan penelitian, yang meliputi berbagai buku teks, jurnal ilmiah, peraturan dan Standar Nasional maupun internasional. Pada permodelan elemen hingga, ada sistem di mana peneliti harus menentukan terlebih dahulu bagaimana dan dengan cara apa mengambil sudut pandang, perlakuan, serta perilaku alami suatu bahan menyusun sampel percobaan tersebut. (2) Modeling, penelitian ini dilakukan dengan bantuan software komputasi ANSYS versi 9.0. Pada permodelan akan dilakukan secara 3D full scale solid element untuk seluruh bagian elemen. Pendeskripsian element types untuk input ANSYS balok tinggi dapat dilihat pada Gambar 3. 


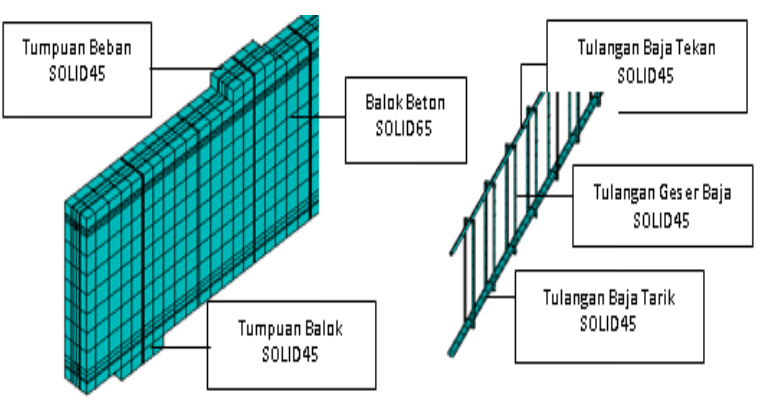

Gambar 3. Element Types untuk Input ANSYS

Tabel 1. Data Model Elemen Balok Beton Bertulang di ANSYS

\begin{tabular}{|c|c|c|c|}
\hline Material & Elemen & Dimensi & $\begin{array}{c}\text { Element } \\
\text { Type }\end{array}$ \\
\hline \hline \multirow{2}{*}{ Beton } & Balok & $\begin{array}{c}800 \mathrm{~mm} \times \\
400 \mathrm{~mm}\end{array}$ & SOLID 65 \\
\hline \multirow{2}{*}{ Baja } & $\begin{array}{c}\text { Tulangan } \\
\text { Tarik }\end{array}$ & $\begin{array}{c}1 \mathrm{D} 22 \\
(\mathrm{As}=628 \\
\left.\mathrm{mm}^{2}\right)\end{array}$ & \multirow{2}{*}{ SOLID 45 } \\
\cline { 2 - 3 } & $\begin{array}{c}\text { Tulangan } \\
\text { Tekan }\end{array}$ & $\begin{array}{c}1 \mathrm{D} 12 \\
(\mathrm{As}=628 \\
\left.\mathrm{mm}^{2}\right)\end{array}$ & \\
\hline \multirow{2}{*}{ Baja } & $\begin{array}{c}\text { Tulangan } \\
\text { Geser }\end{array}$ & $\begin{array}{c}\phi 6-125 \\
\mathrm{~mm}\end{array}$ & \multirow{2}{*}{ SOLID 45 } \\
\hline \multirow{2}{*}{ Baja } & $\begin{array}{c}\text { Tumpuan } \\
\text { Tumpua } \\
\text { n Beban }\end{array}$ & $\begin{array}{c}200 \mathrm{~mm} \mathrm{x} \\
100 \mathrm{~mm} \mathrm{x} \\
50 \mathrm{~mm}\end{array}$ & SOLID 45 \\
\hline
\end{tabular}

Dalam penelitian ini diambil kasus struktur beton bertulang yang tumpuannya mengalami penurunan sebelah akibat daya dukung tanahnya lunak seperti kasus di Banjarmasin. Kemudian penurunan tanah diaplikasikan dengan melakukan menurunan pada salah satu tumpuan. (3) Implementasi Modeling, balok tinggi yang digunakan dalam analisa elemen hingga dengan ANSYS ada dua jenis model, yaitu balok tinggi yang dianalisa sesuai uji eksperimental Arabzadeh, dkk (2011) (balok tinggi validasi) yang menggunakan mutu beton sangat tinggi yaitu $90 \mathrm{MPa}$. Hasil analisis ANSYS nantinya akan menggambarkan perilaku balok tinggi terhadap beban ultimit yang diberikan berupa defleksi, keretakan, dan kehancuran beton. Kemudian hasil tersebut akan dibandingkan dengan hasil eksperimental sebelumnya untuk mendapatkan suatu pola keruntuhan berupa lendutan untimit dan leleh pada balok tinggi. (4) Analisis Hasil, hasil analisis dari ANSYS akan mendapatkan nilai lendutan maksimum dan lendutan daat leleh yang menghasilkan nilai daktilitas kurvatur yang terjadi akibat beban ultimit yang diberikan.

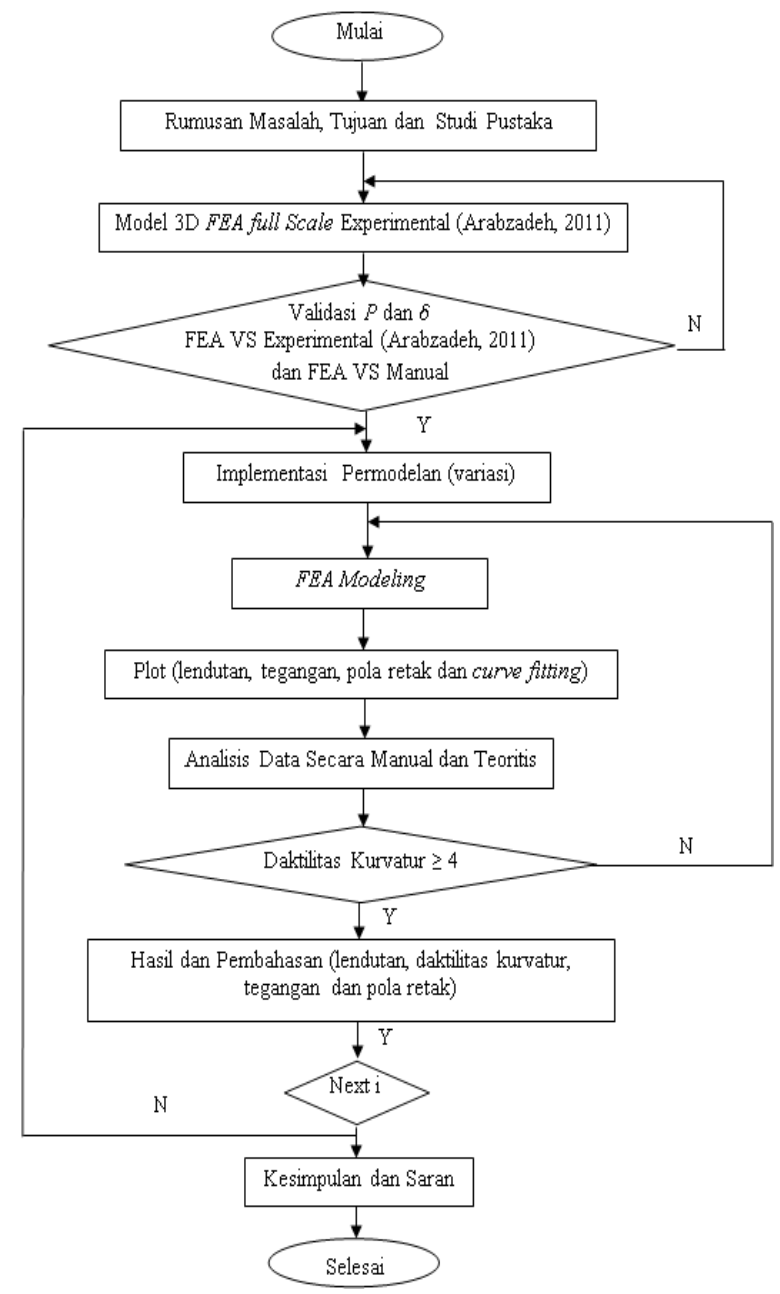

Gambar 4. Diagram Alir Penelitian

\section{Hasil Pembahasan}

Berikut adalah konfigurasi model yang digunakan dalam pemodelan penelitian ini. 
Tabel 2. Konfigurasi model penelitian

\begin{tabular}{|c|c|c|c|c|c|c|}
\hline No & Kode & $\mathrm{fc}^{\prime}$ & $\begin{array}{c}\text { Tul. } \\
\text { Tarik }\end{array}$ & $\begin{array}{l}\text { Tul. } \\
\text { Tekan }\end{array}$ & $\begin{array}{c}\text { Tul. } \\
\text { Geser }\end{array}$ & $\begin{array}{c}\text { Penurunan } \\
\text { Pondasi } \\
\text { (Tumpuan) }\end{array}$ \\
\hline 1 & EA.IM.BT.0 & \multirow{5}{*}{$\begin{array}{c}90 \\
\text { Мpa }\end{array}$} & \multirow{5}{*}{$1 \mathrm{D} 22$} & \multirow{5}{*}{ 1D12 } & \multirow{5}{*}{$\varnothing 6-75$} & $0 \mathrm{~mm}$ \\
\hline 2 & EA.IM.BT.100 & & & & & $100 \mathrm{~mm}$ \\
\hline 3 & EA.IM.BT.200 & & & & & $200 \mathrm{~mm}$ \\
\hline 4 & EA.IM.BT.500 & & & & & $500 \mathrm{~mm}$ \\
\hline 5 & EA.IM.BT.750 & & & & & $750 \mathrm{~mm}$ \\
\hline
\end{tabular}

Keterangan :

EA.IM.BT.XX

EA : Singkatan nama peneliti 1 (Elia Anggarini)

IM : Singkatan nama peneliti 2 (Irwandy Muzaidi)

BT : Balok Tinggi

XX : Nilai penurunan pondasi $(\mathrm{mm})$
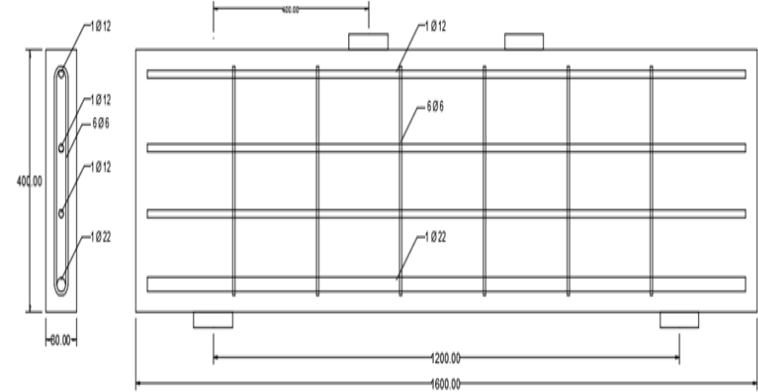

\section{Gambar 5. Balok Tinggi Validasi dan Model}

Berdasarkan hasil dari analisis software ANSYS dapat diketahui nilai beban dan lendutan yang terjadi pada setiap model benda uji.

\section{Model EA.IM.BT.0}

Pada model ini tidak diberikan penurunan pada tumpuan. Dari hasil pemodelan nilai beban maksimum yang dapat dipikul oleh model ini adalah sebesar $300 \mathrm{kN}$ dengan nilai lendutan adalah $1.635 \mathrm{~mm}$.

Diagram kontur lendutan balok model EA.IM.BT.0 pada saat retak pertama dan retak ultimit terjadi pada tengah bentang balok dengan $\mathrm{fc}^{\prime}$ mutu beton sangat tinggi adalah sebesar $90 \mathrm{MPa}$ dapat dilihat pada Gambar 6 dan 7.

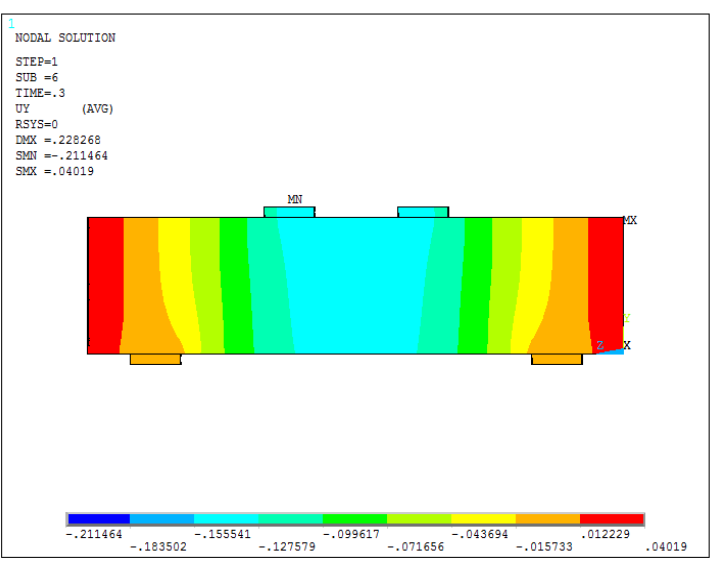

Gambar 6. Diagram Kontur Lendutan Retak Pertama

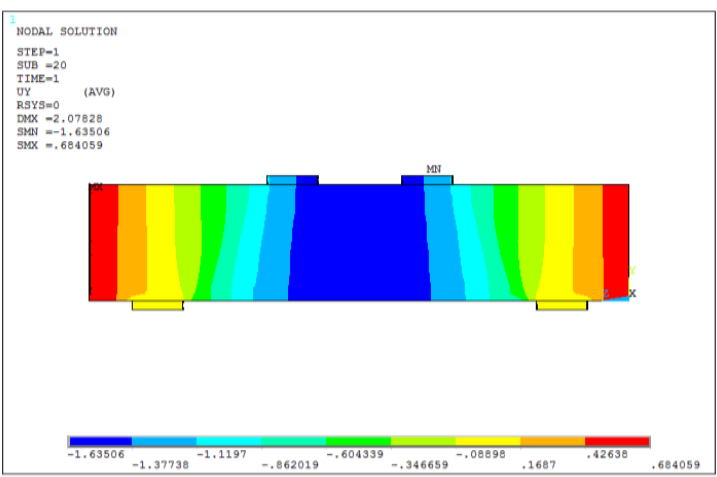

Gambar 7. Diagram Kontur Lendutan Retak Ultimit 
Hasil dari pengujian lendutan balok tinggi model EA.IM.BT.0 dapat dilihat Gambar Grafik 8 berikut.

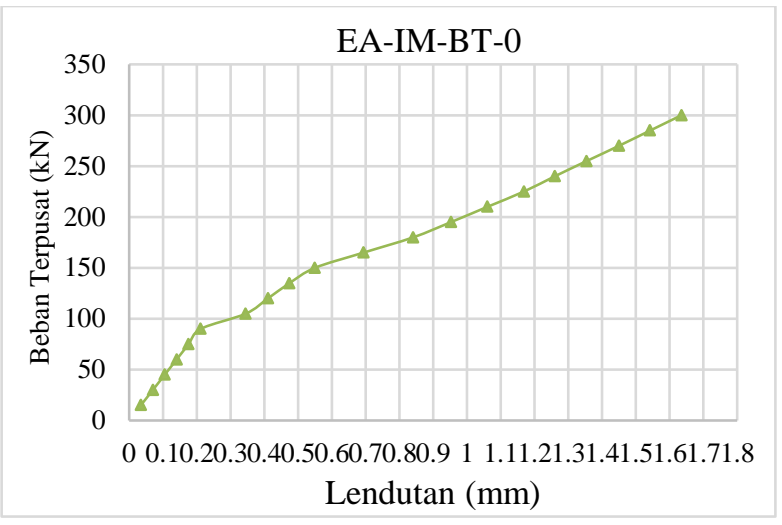

Gambar 8. Grafik P - $\delta$ Model EA-IM-BT-0

\section{Model EA.IM.BT.100}

Pada model ini penurunan pondasi mengalami penurunan sebesar $100 \mathrm{~mm}$ di posisi tumpuan sebelah kanan. Dari hasil pemodelan nilai beban maksimum yang dapat dipikul oleh model ini adalah sebesar $210 \mathrm{kN}$ dengan nilai lendutan adalah 21,012 $\mathrm{mm}$.

Diagram kontur lendutan balok model EA.IM.BT.100 pada saat retak pertama dan retak ultimit terjadi pada tengah bentang balok dengan $\mathrm{fc}^{\prime}$ sebesar $90 \mathrm{MPa}$ dapat dilihat pada Gambar 9 dan 10.

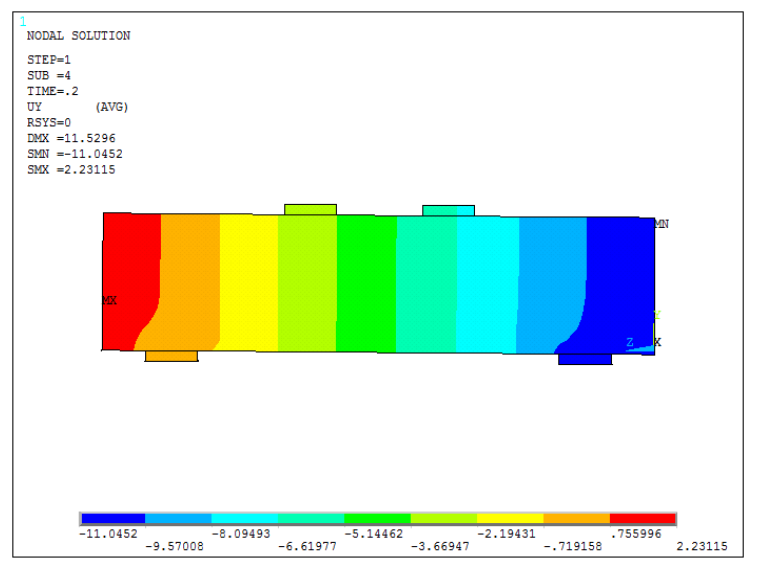

Gambar 9. Diagram Kontur Lendutan Retak Pertama

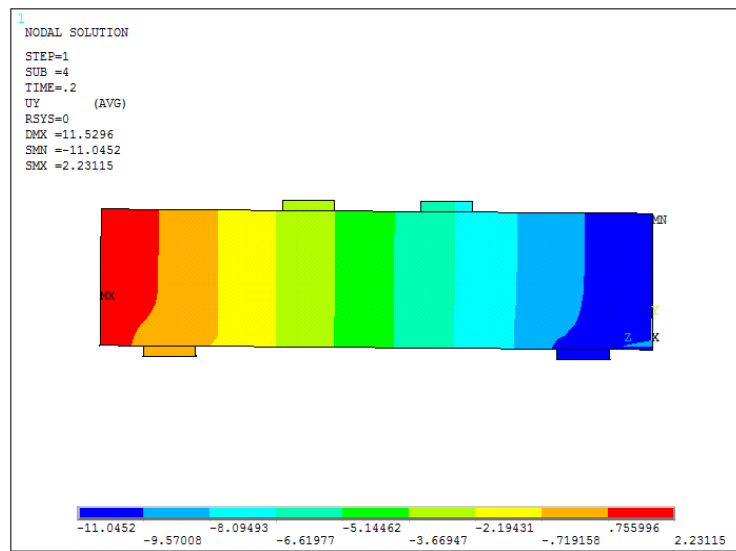

Gambar 10. Diagram Kontur Lendutan Retak Ultimit

Hasil dari pengujian lendutan balok tinggi model EA.IM.BT.100 dapat dilihat Gambar Grafik 11 berikut

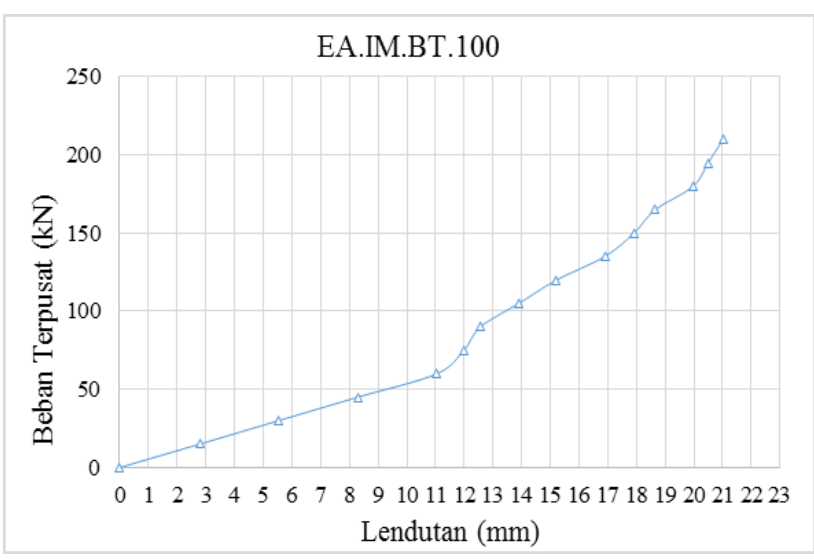

Gambar 11. Grafik P - $\delta$ Model EA-IM-BT100

\section{Model EA.IM.BT.200}

Pada model ini penurunan pondasi mengalami penurunan sebesar $200 \mathrm{~mm}$ di posisi tumpuan sebelah kanan. Dari hasil pemodelan nilai beban maksimum yang dapat dipikul oleh model ini adalah sebesar $65 \mathrm{kN}$ dengan nilai lendutan adalah 23,754 $\mathrm{mm}$

Diagram kontur lendutan balok model EA.IM.BT.200 pada saat retak pertama dan retak ultimit terjadi pada tengah bentang balok dengan $\mathrm{fc}^{\prime}$ sebesar $90 \mathrm{MPa}$ dapat dilihat pada Gambar 12 dan 13. 


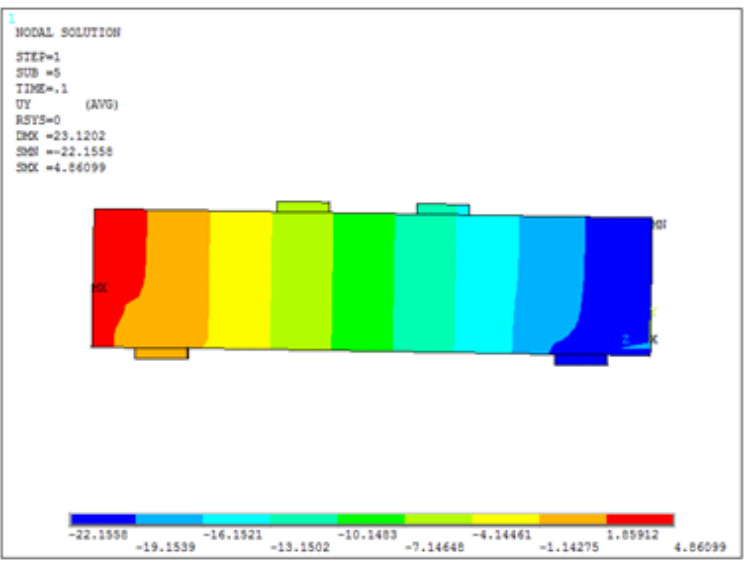

Gambar 12. Diagram Kontur Lendutan Retak Pertama

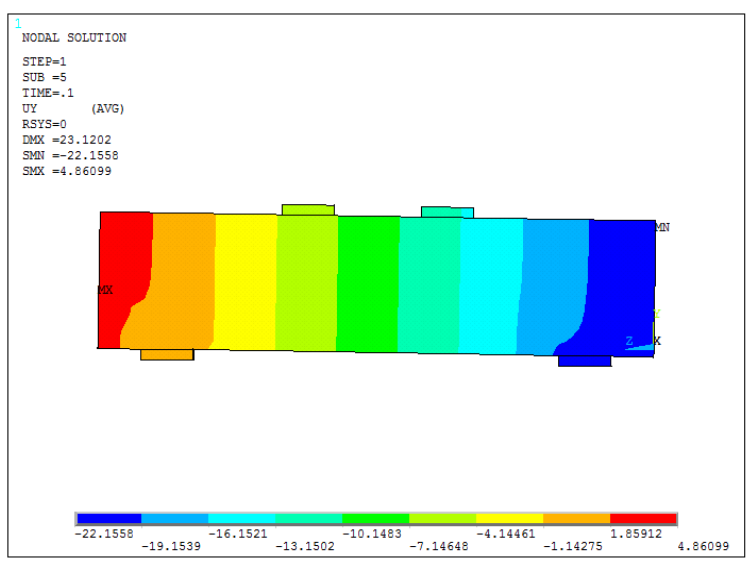

Gambar 13. Diagram Kontur Lendutan Retak Ultimit

Hasil dari pengujian lendutan balok tinggi model EA.IM.BT.200 dapat dilihat Gambar Grafik 14 berikut.

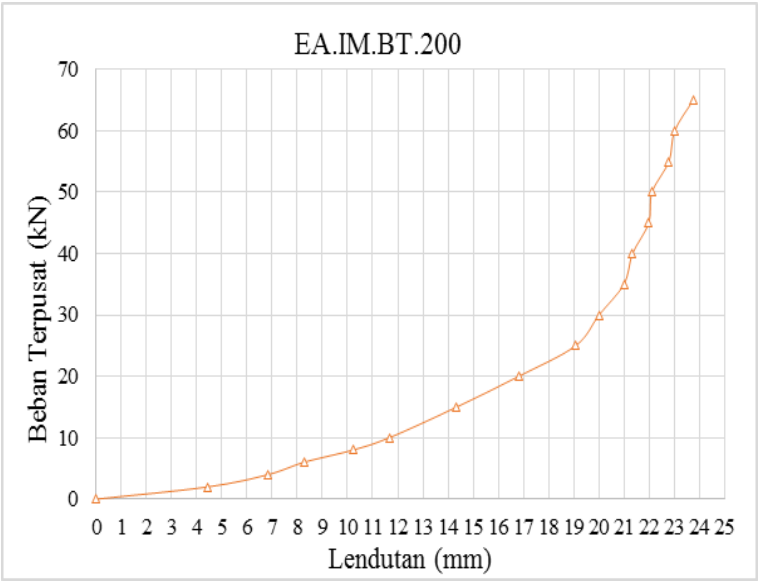

Gambar 14. Grafik $P$ - $\delta$ Model EA-IM-BT200

\section{Model EA.IM.BT.500}

Pada model ini penurunan pondasi mengalami penurunan sebesar $500 \mathrm{~mm}$ di posisi tumpuan sebelah kanan. Dari hasil pemodelan nilai beban maksimum yang dapat dipikul oleh model ini adalah sebesar $55 \mathrm{kN}$ dengan nilai lendutan adalah 22,389 $\mathrm{mm}$.

Diagram kontur lendutan balok model EA.IM.BT.500 pada saat retak pertama dan retak ultimit terjadi pada tengah bentang balok dengan fc' sebesar $90 \mathrm{MPa}$ dapat dilihat pada Gambar 15 dan 16.

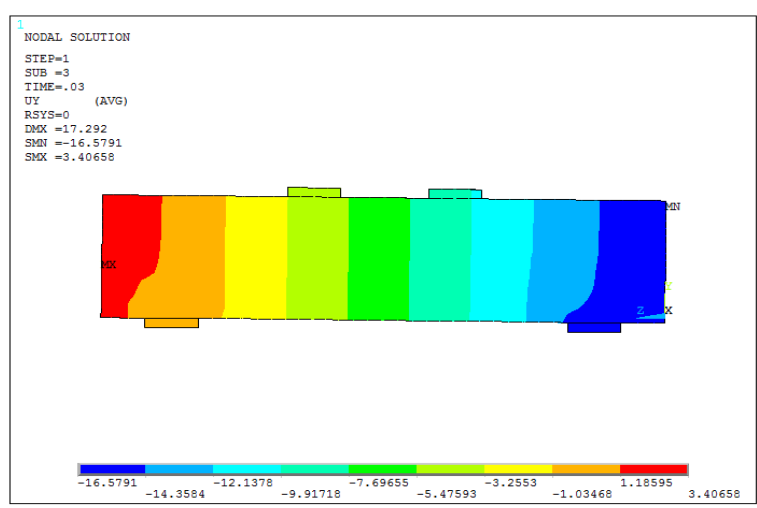

\section{Gambar 15. Diagram kontur Lendutan Retak Pertama}

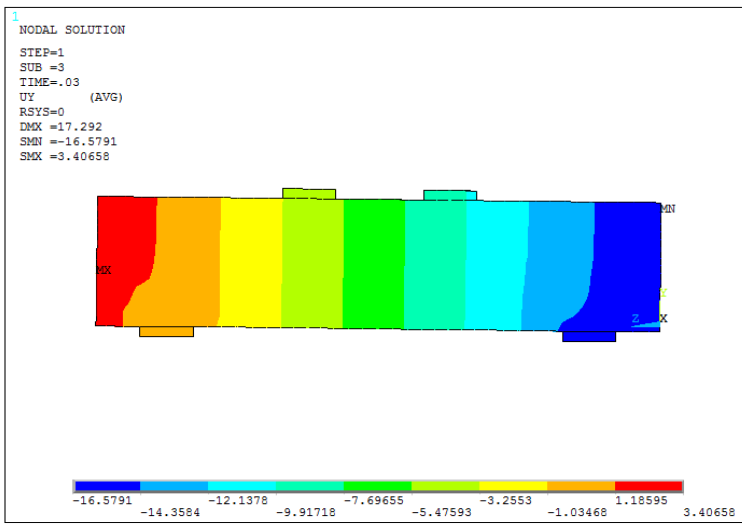

Gambar 16. Diagram Kontur Lendutan Retak Ultimit

Hasil dari pengujian lendutan balok tinggi model EA.IM.BT.500 dapat dilihat Gambar Grafik 17 berikut 


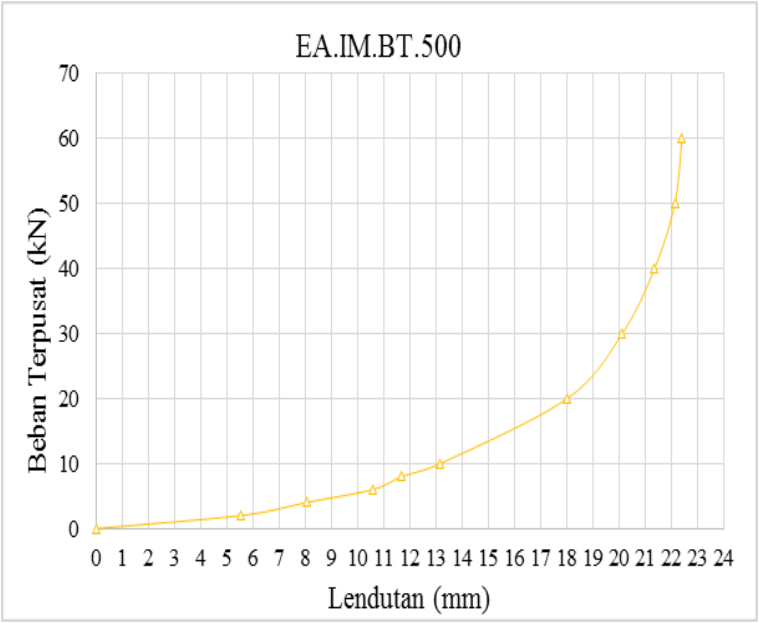

Gambar 17. Grafik P - $\delta$ Model EA-IM-BT500

\section{Model EA.IM.BT.750}

Pada model ini penurunan pondasi mengalami penurunan sebesar $750 \mathrm{~mm}$ di posisi tumpuan sebelah kanan. Dari hasil pemodelan nilai beban maksimum yang dapat dipikul oleh model ini adalah sebesar $130 \mathrm{kN}$ dengan nilai lendutan adalah 24.022 $\mathrm{mm}$

Diagram kontur lendutan balok model EA.IM.BT.750 pada saat retak pertama dan retak ultimit terjadi pada tengah bentang balok dengan $\mathrm{fc}^{\prime}$ sebesar $90 \mathrm{MPa}$ dapat dilihat pada Gambar 18 dan 19.

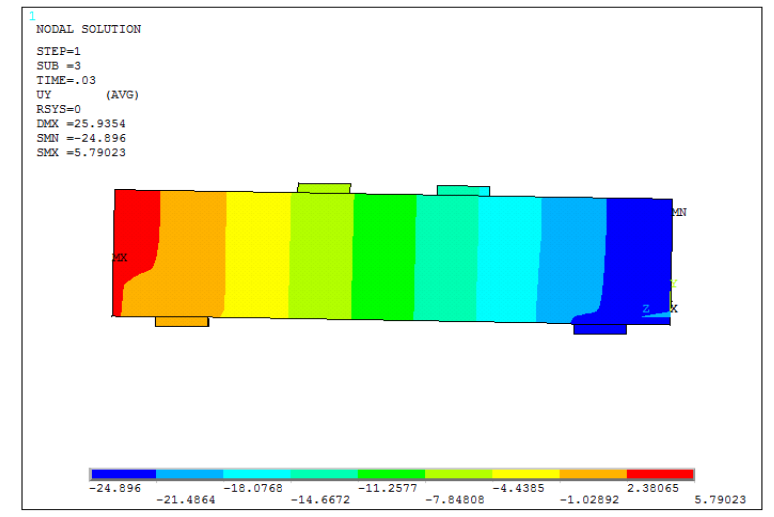

Gambar 18. Diagram Kontur Lendutan Retak Pertama

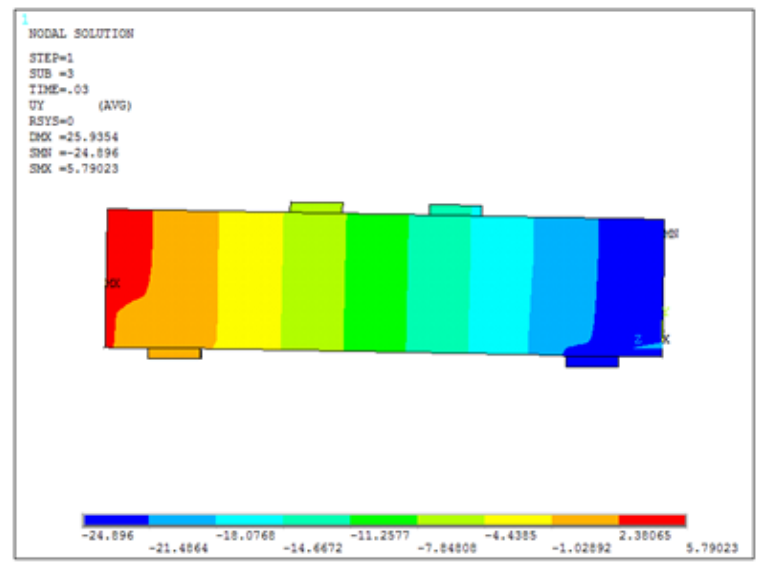

Gambar 19. Diagram Kontur Lendutan Retak Ultimit

Hasil dari pengujian lendutan balok tinggi model EA.IM.BT.750 dapat dilihat Gambar Grafik 20 berikut

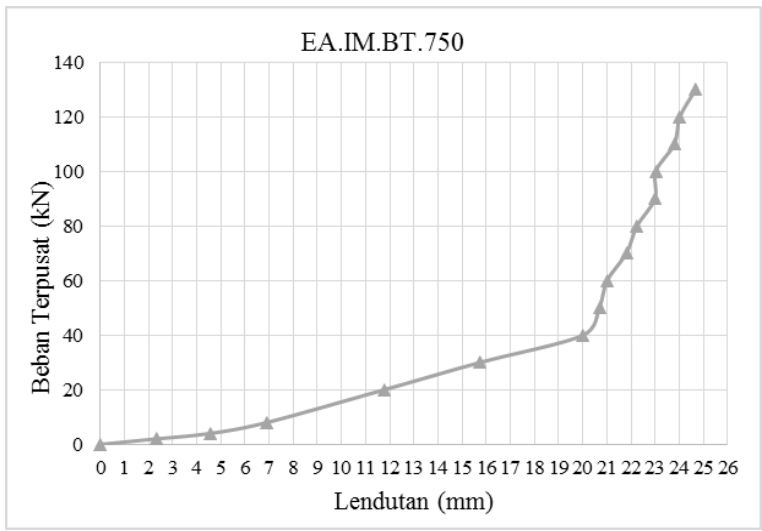

Gambar 20. Grafik P - $\delta$ Model EA-IM-BT750

Sedangkan hubungan lendutan maksimum dengan model balok seperti di bawah ini.

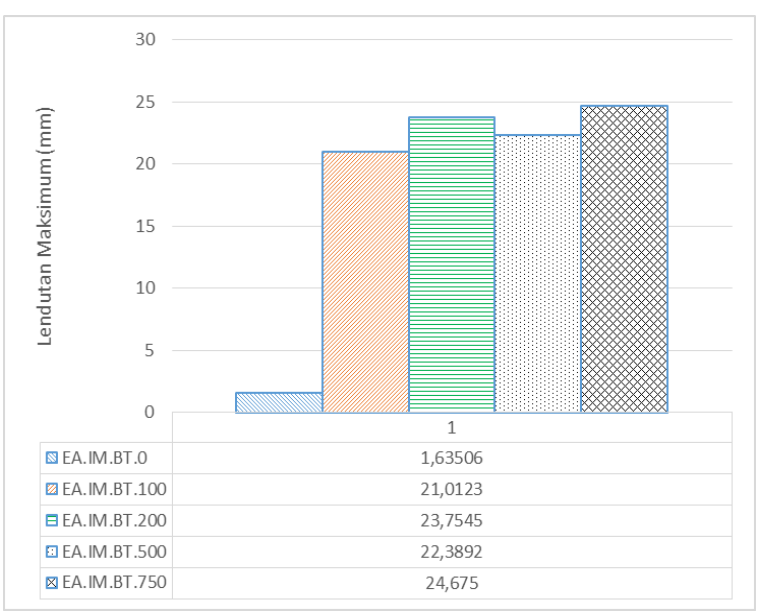

Gambar 21. Grafik Lendutan Maksimal 
Hasil dari pengujian lendutan Balok Tinggi Beton Beton Mutu Tinggi menggunakan FEA ANSYS pada dilakukan menghasilkan peningkatan nilai lendutan pada balok tinggi yang pondasinya mengalami penurunan sangat signifikan.

\section{Hasil Pengujian Daktilitas Kurvatur}

Hasil dari pengujian daktilitas kurvatur balok tinggi beton beton mutu tinggi menggunakan FEA ANSYS dapat lihat pada Tabel 3 dan Gambar 21 berikut.

Tabel 3. Nilai Daktilitas Kurvatur Pada Model Balok Tinggi

\begin{tabular}{|c|c|c|c|}
\hline $\begin{array}{c}\text { Kode } \\
\text { Balok }\end{array}$ & $\begin{array}{c}\text { Kurvatur } \\
\text { Leleh }\end{array}$ & $\begin{array}{c}\text { Kurvatur } \\
\text { Ultimit }\end{array}$ & $\begin{array}{c}\text { Daktilitas } \\
\text { Kurvatur }\end{array}$ \\
\hline Model 1 & 0.211 & 1.635 & 7.733 \\
\hline Model 2 & 12.564 & 21.012 & 1.672 \\
\hline Model 3 & 20.009 & 23.755 & 1.187 \\
\hline Model 4 & 20.109 & 22.389 & 1.113 \\
\hline Model 5 & 21.009 & 24.675 & 1.175 \\
\hline
\end{tabular}

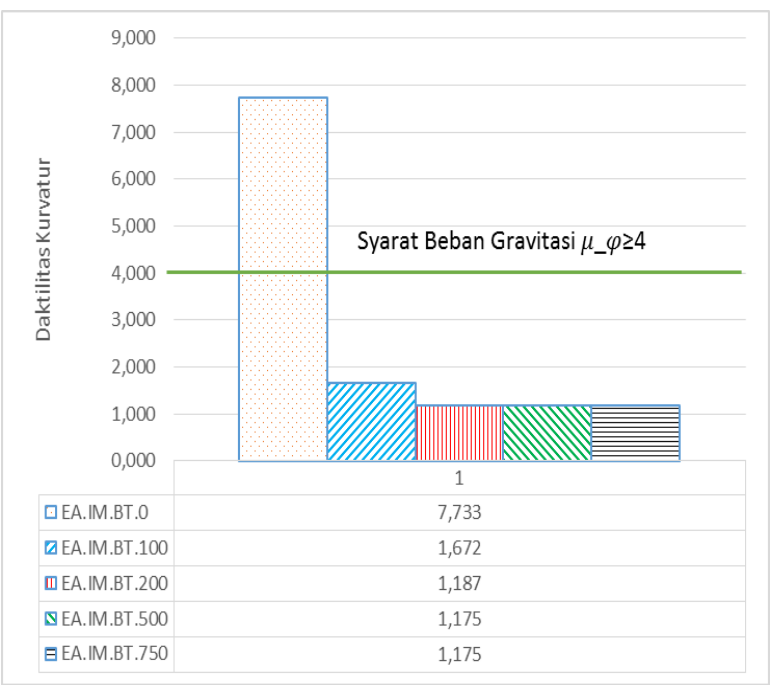

Gambar 22. Grafik Daktilitas Kurvatur

Dari Gambar 22 dapat diketahui bahwa pada balok tinggi yang mengalami penurunan pada pondasinya memiliki nilai daktilitas kurvatur kurang dari 4 (syarat untuk beban gravitasi) yang menyebabkan balok tinggi bersifat getas. Sehingga perencana pondasi pada suatu perencanaan konstruksi bangunan harus diperhitungkan dengan sungguh-sungguh agar penurunan pondasi tidak terjadi.

\section{Kesimpulan}

Berdasarkan analisis terhadap data dan hasil pengolahan yang dilakukan dihasilkan kesimpulan yang sesuai dengan tujuan penelitian yaitu :

Dari hasil permodelan dengan bantuan software ANSYS diketahui bahwa pada balok tinggi yang mengalami penurunan pada pondasinya memiliki nilai daktilitas kurvatur kurang dari 4 (syarat untuk beban gravitasi) yang menyebabkan balok tinggi bersifat getas. Sehingga perencana pondasi pada suatu perencanaan konstruksi bangunan harus diperhitungkan dengan sungguh-sungguh

\section{Daftar Pustaka}

Arabzadeh. A, R. Aghayari, Ali Reza Rahai (2011), Investigation of Experimental and Analytical Shear Strength of Reinforced Concrete Deep Beams. International Journal of Civil Engineering.

Darmansyah Tjitradi, Eliatun Eliatun and Syahril Taufik (2017), 3D ANSYS Numerical Modeling of Reinforced Concrete Beam Behavior under Different Collapsed Mechanisms, International Journal of Mechanics and Applications, Volume 7(1): pp. 14-23 DOI:

10.5923/j.mechanics.20170701.02.

Darmansyah Tjitradi (2015), Permodelan

Perilaku Keruntuhan Balok Tinggi Beton Bertulang Menggunakan Ansys, Program Magister Teknik Sipil Universitas Lambung Mangkurat, Banjarmasin. 
Das, B.M., 2008, Advanced Soil Mechanics, edisi 3, Taylor and Francis, USA.

Handiyatmo, C.H., 2003, Mekanika Tanah, Beta Offset, Yogyakarta

Iswan, dkk. 2016. Study Analisis Penurunan Tanah Lempung Lunak dan Lempung Organik Menggunakan Pemodelan Matras Beton Bambu dengan Tiang. Jurnal Rekayasa, Vol. 20, No. 3.

K.Suknam, and H. Andrew G. 2004. Average Degree of Consolidation in Normally Consolidated Soil Considering the Change of Coefficient of Consolidation with Time. Electronic Journal of Geotechnical Engineering

Marzuki Akhmad, Alpiannor, (2016), Evaluasi Kegagalan Pondasi Pada Gedung Bertingkat (Studi Kasus: Proyek Pembangunan Ruko 3 Lantai - Banua Anyar Banjarmasin), Prosiding Seminar Nasional Geoteknik.

P, Yudi dan S. Riza. 2017. Evaluasi Penurunan Gedung Dan Metode Perbaikannya (Studi Kasus: Kantor Pos Balikpapan). Jurnal Teknik Mesin (JTM): Vol. 06, No. 2

S. Handali, dkk. 2013. Pola Kerusakan Bangunan Di Tanah Lempung Ekspansif Di Ngawi Jawa Timur. Majalah Ilmiah UKRIM Edisi 1.

Swami P. S, Patil S. S, and Kore P. N, (2015), Behavior Of Concrete Deep Beams With High Strength Reinforcement, International Journal of Current Engineering And Scientific Research (Ijcesr) Volume-2, Issue-9.

Umesh Wani, Prof. Sanjay Bhadke (2017), Deep Beam Analysis Using FEM Program and ANSYS for ISO - parametric elements, International Journal of Innovative Research in Science, Engineering and Technology Vol. 6, Special Issue 11
Wight, J.K., MacGregor, J.G. (2012). Reinforced Concrete: Mechanics \& Design, 6th ed. Pearson (New Jersey) 